\title{
Negotiating Legacies
}

\section{Opposing, Interrupting, Re-creating-Taiwan's ongoing Experience}

\author{
Lara Momesso \\ University of Central Lancashire, Preston, U K \\ lmomesso@uclan.ac.uk \\ Niki J.P. Alsford \\ University of Central Lancashire, Preston, UK \\ njpalsford@uclan.ac.uk
}

\begin{abstract}
This special issue concerns agency and negotiation in the context of the hierarchical relations between the People's Republic of China (PRC), a global superpower, and Taiwan, a subordinated actor often relegated to a marginal position in contemporary global geopolitics. By exploring how Taiwan opposes, interrupts and re-creates its subordinate position vis-à-vis China, the authors of this special issue will shed light on the complexities of the ongoing Taiwan experience, shaped by different, often opposing, interests, positions and perspectives regarding its relationship with China. Yet, by exploring the experience of Taiwan with reference to its Chinese legacies, this special issue will also allow important reflections on China, not only in its hegemonic role regionally and globally, but also in its weaknesses when it deals with subordinated actors. This is a timely and important piece, which will allow alternative interpretations of contemporary events not only in Taiwan, for instance the recent national elections and related political developments, but also in the region, such as the protests which have been occurring in Hong Kong during the last four months.
\end{abstract}

\section{Keywords}

Taiwan - China - Taiwan subjectivity - other Chinese realities - negotiation 
Seven months have passed since the last presidential and legislative elections were held in the Republic of China (ROC) on Taiwan. In January 2020, Tsai Ing-wen of the Democratic Progressive Party conveniently won re-election in the presidential race and also secured a second-term majority in the legislature, marking the first time that a party could continue to govern alone as a majority. In the first four years of Tsai's tenure as president, a number of events transpired that served as justification for Taiwan to distance itself socially, economically and politically from the influence of China. Not only has President Tsai refused to explicitly recognise the 1992 Consensus and its core implications building on the One China Principle, but she has also worked to develop alternative economic policies that could contribute to diversifying Taiwan's sphere of economic and social cooperation and exchanges and to reducing the influence of China on the island. ${ }^{1}$ This has been coupled with a public narrative that sheds light on the negative impact that China may have on Taiwan's democracy, sovereignty and freedom. These top-down decisions should also be interpreted in light of bottom-up social changes suggesting that Taiwan has been increasingly less connected to the Chinese sphere of influence. Identification seems to reveal quite a lot in this regard. Statistical accounts suggest that an identity shift has been occurring among the Taiwanese population, particularly among the island's youth, with a drastic increase in the percentage of people who viewed themselves as Taiwanese against a constant decrease in the proportion of people who identified with any connection to Chineseness. ${ }^{2}$ The ongoing situation in Hong Kong has served as a wake-up call to many, illustrating that the boundaries of the status quo in Taiwan have been moved.

Yet any move that is perceived as deviating from the accepted position in China has not gone down well among Chinese leaders. They have responded to Tsai's electoral victory in various ways: they returned to the old game of 'dollar diplomacy', with the purpose of poaching the island democracy's allies and isolating Taiwan internationally; they reduced the flow of group tourists from China, attempting to engender losses in areas of Taiwan's economy; they continue to pressure multinational companies, public services and educational

1 For instance, the New Southbound Policy is one of these: Alan H. Yang, 'Unpacking Taiwan's presence in Southeast Asia: the international socialisation of the New Southbound Policy', Issues and Studies: A Social Science Quarterly on China, Taiwan and East Asian Affairs 54, 1 (2018): 1840003-33.

2 Election Study Center, National Chengchi University, 'Latest graphs of Taiwanese core political attitude trend (1992-2019/20)', posted o3 July 2020, https://esc.nccu.edu.tw/course/news .php?Sn=166 (accessed o9 July 2020). 
institutions to comply with the One China policy and other Beijing standards, reducing Taiwan's access to the international community. Relatively quickly, a harsh reality presented itself to the Taiwanese nation, namely the difficulty it would have standing on its own in a world under the influence of a growing global superpower.

Scholars from all disciplines have done incommensurable work to catch up with these rapid developments. Yet the literature seems to be fragmented, favouring either the perspective of China, as a powerful and hegemonic power where others have no other option but to obey and comply, or that of Taiwan, as an entity on its own, a democracy, with the capability of bypassing China's influence through its informal international diplomacy and its strong domestic stance against China. The current pandemic has most definitely impacted how Taiwan is viewed, though this improved reputation may prove to be ephemeral.

The reality, however, is more sophisticated and complex. Subordination and resistance are hardly absolute categories; they often coexist with each other and change each other. Along this line, the papers presented in this special issue will shed light on the complex and ongoing relationship that Taiwan has with China, in its attempt to (re)negotiate the legacies of its 'Chinese' past, (re)define a suitable national narrative for its present, and decide on a direction for its future. As such, this special issue aims to shed light on the complexity of the ongoing Taiwan experience, shaped by different, often opposing, interests, positions and perspectives with regard to its relationship with China. By shedding light on the complexity of Taiwan's ongoing experience of negotiation with the legacies of an order that was imposed on it decades ago, the papers in this special issue will make explicit the power dynamics between China and Taiwan, sometimes in favour of the former and other times in favour of the latter.

In this special issue we build on the idea that power, subordination and resistance coexist with each other and generate a two-way process of negotiation between hegemonic powers and subordinated actors. Emirbayer and Mische use the expression 'double construction of agency and structure' to emphasise the fact that the negotiation between different actors in a hierarchical system is fundamental when exploring social phenomena. ${ }^{3}$ We extend this conceptuali-

3 M. Emirbayer and A. Mische, 'What is agency?' American Journal of Sociology 103, 4 (1998): 1004 . 
sation to shed light on Taiwan's agency when negotiating with the hegemonic power of China. In a clearly constructivist approach, we see China as the actor with the capacity, power and resources to impose its will on Taiwan against its wishes. Yet we also see China as a powerful actor that is challenged by Taiwan in various ways and, eventually, needs to adjust to it. This negotiation eventually will bring change on both sides.

Building on these reflections, this special issue will address the following core questions: first, in opposing, interrupting and re-creating its past and present relationship with China, what is it that the Taiwanese state and its people are reacting to? Second, how can this condition help us to better understand the experience of Taiwan and, by extension, that of the PRC, in past and present times? Third, what identities and social groups better help us in our attempt to shed light on this negotiation?

With the aim of addressing these timely issues, this special issue brings together six established scholars in the field of Taiwan Studies, who will explore this conundrum in the experience of Taiwan, as both a powerful and powerless actor against the hegemon on the other side of the Taiwan Strait. By answering the research questions from different disciplinary angles and applying both qualitative and quantitative methods, the six papers of this special issue will take the reader through an interesting journey in which it is possible to explore how Taiwan resists, accommodates, defies, challenges the hegemonic power of China. Without doubt, the strength of this collaborative project is its interdisciplinary character, made possible by the different academic background of the six authors. It has been extensively argued that interdisciplinarity is a powerful tool to solve complex problems and integrate knowledge that individual disciplines cannot solve alone. ${ }^{4}$

The first group of papers offers important reflections on knowledge production regarding Taiwan in academic and literary debates.

Taiwan has to fight for recognition in academic debates, particularly in mainstream Western discourse, where it has a marginal position and is often treated as a subfield of China Studies. Yet Niki Alsford's paper, 'Finding the threads in Taiwan history and historiography', argues that Taiwan has, since the sixteenth century, been a site of attention among travellers, academics and writers. These encounters have also produced a rich amount of data and metadata on Taiwan. By charting the evolution of Taiwan's historiography, Alsford

4 J.A. Jacobs and S. Frickel, 'Interdisciplinarity: a critical assessment', Annual Review of Sociology 35 (2009): 43-65; J. Groen and T. Hyland-Russell, 'Stepping out: collaborative research across disciplines', International Journal of Qualitative Studies in Education 29 (2016): 814-826; doi:10.108o/o9518398.2016.1162867. 
argues that those who have engaged with Taiwan have inevitably referenced its differences in its comparison to its regional other. Within this context, Alsford celebrates Taiwan's marginality as an opportunity to add to larger existing debates within various academic fields and disciplines.

Remaining within the field of historiography, Ann Heylen's 'Diaries and oral histories as ego-documents in the representations of the Taiwanese nation' explores the potential of personal documents, such as diaries, oral histories and memoirs, in shaping the definition of new historical narratives. Negotiation, in this case, operates at multiple levels and in different directions. A first dimension may be the rewriting of the history of a nation that has been oppressed and silenced by other powers in past times, particularly the Japanese and the Chinese. Yet another dimension can be the deconstruction of a more contemporary mainstream Taiwan-nation-centric discourse on Taiwan's past. In this context, ego-documentaries can help unfold the many subjective histories of Taiwan, which have remained hidden until now.

Ti-han Chang, with her paper, titled 'Shaping Taiwan's history through nonhuman agents: Wu Ming-yi and his postcolonial ecological writings', moves the discussion to literary debates. In a paper that crosses the lines between history, literature and environmental sciences, Chang discusses how a contemporary renowned Taiwanese writer, Wu Ming-Yi, took a drastic turn away from Taiwan's Chinese legacy by foregrounding non-human agents, such as butterflies, elephants, a bird, fish-men and a bamboo forest. Wu Ming-yi's ecological works can be seen to possess a unique quality, for they offer a new landscape and an alternative path for the general development of postcolonial writing in Taiwan, reaction to a homogenous political and historical discourse of shared identities and cultures within sinophone societies.

The last three papers offer snapshots of negotiation rooted in the empirical reality.

Adina Zemanek's contribution, 'Travel, cultural hybridity and transnational connections in Taiwanese graphic narratives', investigates how transnational connections and cultural diversity have been strategised to define new concepts of Taiwaneseness by graphic novelists in contemporary times. Taking a different trajectory from Heylen's account of rupture through self-rediscovery, Zemanek looks at negotiation through expansion, namely in Taiwan's transnational links with Europe, New Zealand and Hong Kong.

Táňa Dluhošová's paper, 'Marital networks and portfolios of prestige: Digital Humanities perspectives on the study of Taiwanese elites', explores the origin of some of the top Taiwanese companies in contemporary times, connected to the so-called new prominent Taiwanese families in Japanese colonial times and the first years of the early post-war period. By employing an innova- 
tive approach that combines Digital Humanities and sociological methods, the author explores the heterogeneous world of Taiwanese elites and their engagement in politics, business, culture and administration. This paper opens a new window to our understanding of social mobility in Taiwan, suggesting that a study of Taiwanese elites should not only be limited to the sphere of Taiwan, but should also be extended to China, where a certain social and political structure was established during the first years of the Republican Period.

Finally, Lara Momesso's paper, 'Chinese marriage migrants in Beijing's crossstrait diplomacy', diverts the attention to the role of new immigrants to Taiwan, particularly immigrants of Chinese origins married to Taiwanese citizens, in shaping new forms of relationships and dynamics with their motherland, the PRC. By shedding light on more recent public diplomacy practices enacted by Beijing and targeting PRC marriage migrants residing in Taiwan, this paper reminds the reader that in the interlocking process of 'staging' and 'performing', which reflects migrant/state negotiation in the sphere of public diplomacy, the most powerful may dictate the transcript but it may not necessarily have full control of the final meaning of the performance.

Adam Lifshey, professor of Spanish and Portuguese at Georgetown University, refers to the experience of Taiwan as something non-Worldly. That is to say, Taiwan navigates global governance under varying pseudonyms. These are the result of contested negotiations: never sovereign. For Lifshey, Taiwan exists in the world, but not in the World. ${ }^{5}$ Thus, as the papers of this special issue also highlight, to understand Taiwan is to navigate Taiwan. Those who have chosen Taiwan as their site of research have done so because they are encouraged to make comparative links within and without the boundaries of its relationship with China, yet always locating Taiwan's subjective experience at the centre of their attention.

\section{3}

\section{Conclusion}

Taken all together, these papers will constitute significant material to critically assess the visible and invisible consequences of China's rise from a perspective that is often overlooked, that of other Chinese realities. In this special issue, the ongoing experience of Taiwan is multifaceted, in its relationship with China (re-creating and opposing) and in the alternative routes conceived by its society and government (interrupting). Finally, by shedding light on negotiation

5 Adam Lifshey, 'On the third hand: why to taiwan World Literature', Ex-Position 41 (2019), 125. 
rather than mere submission, this special issue will offer us the opportunity to understand China from an alternative angle, that of a global power that not only shapes but also is shaped by minor, invisible, non-mainstream others.

There is not a more significant moment to engage in a discussion of negotiation between China, a global superpower, and Taiwan, a marginal actor in contemporary global geopolitics. The aim of this special issue, against a literature that stresses Taiwan's dependence on China, on the one hand, and depicts China as the actor with the capacity, power and resources to impose its will on Taiwan, on the other hand, is to offer a more complex picture rich in contradictions, tensions and possibilities.

\section{References}

Election Study Center, National Chengchi University. 'Latest graphs of Taiwanese core political attitude trend (1992-2019/20)', posted o3July 2020, https://esc.nccu.edu.tw/ course/news.php?Sn=166 (accessed o9 July 2020).

Emirbayer, M., and A. Mische. 'What is agency?' American Journal of Sociology 103, 4 (1998): 962-1023.

Groen, J., and T. Hyland-Russell. 'Stepping out: collaborative research across disciplines'. International Journal of Qualitative Studies in Education 29 (2016): 814-826; doi:10.108o/o9518398.2016.1162867.

Jacobs, J.A., and S. Frickel. 'Interdisciplinarity: a critical assessment'. Annual Review of Sociology 35 (2009): $43^{-65}$.

Lifshey, Adam. 'On the third hand: why to taiwan World Literature'. Ex-Position 41 (2019): $125^{-136 .}$

Yang, Alan H. 'Unpacking Taiwan's presence in Southeast Asia: the international socialisation of the New Southbound Policy'. Issues and Studies: A Social Science Quarterly on China, Taiwan and East Asian Affairs 54, 1 (2018): 1840003-33. 